\title{
SYNTHESIS OF HYDROCARBON FUELS VIA SELECTIVE REFORMING OF KEROSENE OVER VARIOUS NI/ZEOLITE CATALYSTS
}

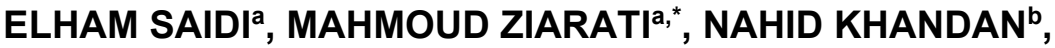 \\ HOSSEIN DEHGHANI ${ }^{\mathrm{a}}$
}

\begin{abstract}
In this study, the reforming of kerosene was performed in a fixed-bed reactor in order to investigate the synthesis of hydrocarbon fuels. For this purpose, five Ni-based catalysts supported on Y, Mordenite, ZSM5, Beta, and Ferririte zeolites were prepared by deposition-precipitation method. Four main composition groups of hydrocarbons including normal paraffins, isoparaffins, cycloparaffins, and aromatics were analyzed in feed and liquid products and the effects of key parameters of the catalysts namely acidity, diameter of pores in channels, and surface area on the progress of the reforming process were surveyed. According to the analysis results, $Y$ zeolite with higher acidity, larger pore diameter, and more surface area led to produce the most aromatic contents (57.60\%) in the products. Beta increased both cycloparaffins (34.91\%) and isoparaffins $(34.07 \%)$ in the product. Mordenite and Ferririte effectively increased the formation of isoparaffins by $38.22 \%$ and $38.85 \%$ respectively. Meanwhile, ZSM-5 with moderate acidity, surface area, and pore size increased the cycloparaffin contents of the product $(46.28 \%)$. These results highlighted the potential of each zeolite to produce a valuable product via reforming process, which meets the requirement of standard hydrocarbon fuels. Ultimately, the pathway to reforming process over each prepared catalyst was proposed.
\end{abstract}

Keywords: Reforming process, Bi-functional catalysts, Zeolite, Kerosene, Jet fuel, Reaction pathway

\section{INTRODUCTION}

Fossil fuels including petroleum, natural gas, and coal produced $80 \%$ of the energy consumed worldwide in 2018. This share is estimated to decrease only slightly $(70 \%)$ by 2050 [1]. The transportation as a fast growing

a Malek- Ashtar University of Technology (MUT), Faculty of Chemistry and Chemical Engineering, Lavizan, P.O. BOX 158751774, Tehran, Iran

b Iranian Research Organization for Science \& Technology (IROST), Department of Chemical Technologies, P.O. BOX 33535111, Tehran, Iran

Corresponding author: maziarati@mut.ac.ir 
sector, particularly in developing countries, however is relied almost entirely $(95 \%)$ on petroleum. Hence, it has lower probability to undergo these changes $[2,3]$. By development of modernity in the world, the aviation as a transportation sector developed highly more than other sectors such that the need to jet fuels grew annually [4]. The petroleum-derived fuels utilized in these sections commonly contain four main compositions including line and branched paraffins, cycloparaffins, and aromatics [5]. There are several processes to produce or enhance the fuels by conversion of these components to each other through various reactions such as isomerization, hydrogenation and dehydrogenation, which are categorized as the reforming of hydrocarbons [6]. According to the previous literatures, many researchers have produced hydrocarbon fuels from several sources such as Fisher- Tropsch process [7], biomass and other wastes [8, 9], vegetable oils, etc. [10, 11]. However, the availability, easy access, and low price of oil-derived fuels makes them this chance to be applied as a feed for reforming process. Among them, kerosene is the third fraction of crude oil, which has the lowest $\mathrm{H} / \mathrm{C}$ ratio and between 9 to 16 carbons. It was applied as a base for many jet fuels. Therefore, it was selected as a feed to reforming process in this research.

Several catalysts were employed for conversion of the hydrocarbons due to their undeniable advantages in comparison to traditional thermal reforming [12]. Catalytic reforming of hydrocarbon fractions is among the crucial processes in the oil refineries and petrochemical companies [13-15]. Among the various classifications of the homogeneous and heterogeneous catalysts namely acid, base, and zeolite catalysts, several valuable abilities of zeolites such as having acid-base character, low cost, environmentally friendly, uniform pore structure, high surface area and porosity, and reusability caused many researchers apply them widely to reforming of hydrocarbons [16]. In fact, their Lewis and Brønsted acid sites can efficiently go the reactions ahead the desirable route. This helps to form a final liquid product with high $\mathrm{H} / \mathrm{C}$ ratios, which has the capability to utilize as a high energy fuel [17]. Zeolite catalysts have commonly employed as support of catalysts for major refining processes such as fluid catalytic cracking, distillate dewaxing by cracking, hydrocracking, lube dewaxing by cracking, gasoline desulfurization, distillate dewaxing by isomerization, light paraffin isomerization, lube dewaxing by isomerization, reformate upgrading and diesel aromatics saturation, and they have shown promising catalytic performance in the reforming process $[18,19]$. As the individual advantage of zeolite in comparison to the conventional catalysts, they could provide the unique feature of shape selectivity due to their repeatable pore structure useful to the reaction under consideration. For example, zeolite with more dimensional pore channel structure can provide a higher cracking activity than 1D ones. It is because of longer contact time of molecules in the pore [20]. 
Introduction of metals to zeolites is favorable for catalytic reforming process, because of preserving acid sites and increasing the production of the lighter hydrocarbons by progress the reaction towards the desirable pathway. Nickel (Ni) with low cost, effective activity, and more availability is the most widely used with zeolites for the reforming of hydrocarbons [11, 2127]. High metal loadings cause bulk Ni particles $(>10 \mathrm{~nm})$ in the catalysts that harden access to internal zeolite pores [28]. Therefore, an ideal metal loading is necessary to influence the porosity and acidity of the zeolite in a positive way [29-31]. In this work, the $5 \% \mathrm{Ni}$ loading for $\mathrm{Ni} / \mathrm{Y}$ catalysts were employed to prepare the catalysts.

However, reports on the reforming of kerosene over zeolites are still rare and the vital role of various zeolites in the reforming of the hydrocarbon fuels has rarely studied in details. In light of this, five different zeolites (Ferririte, Mordenite, ZSM-5, $\beta$-zeolite, and Y-zeolite) were employed for catalytic reforming of kerosene in this research. Ultimately, the composition of products over each zeolite was discussed to determine the suitable zeolites to produce a standard fuel via reforming of kerosene.

\section{RESULTS AND DISCUSSION}

\section{Structural properties}

As indicated in Figure 1, XRD patterns reported for the calcined catalysts is clearly displayed the structures of catalysts without any contamination by impure phases. Therefore, the framework of zeolite seems to be maintained well after incorporation of nickel but its crystallinity slightly changed by synthesis. In this study, only some of the peaks of $\mathrm{NiO}$ were distinguished. One reason may be the size of the particles, which might be below the detection limit of $X R D$. As suggested in some literatures, the characteristic diffraction peaks of $\mathrm{Ni}$ crystallized from some prepared zeolite catalysts such as $\mathrm{Ni} / \beta$ are very weak (Figure 1) which means the poor crystallinity of Ni on these catalysts. It is in agreement with the highly dispersive of oxide on the support and smaller sizes than detected by XRD [32]. 


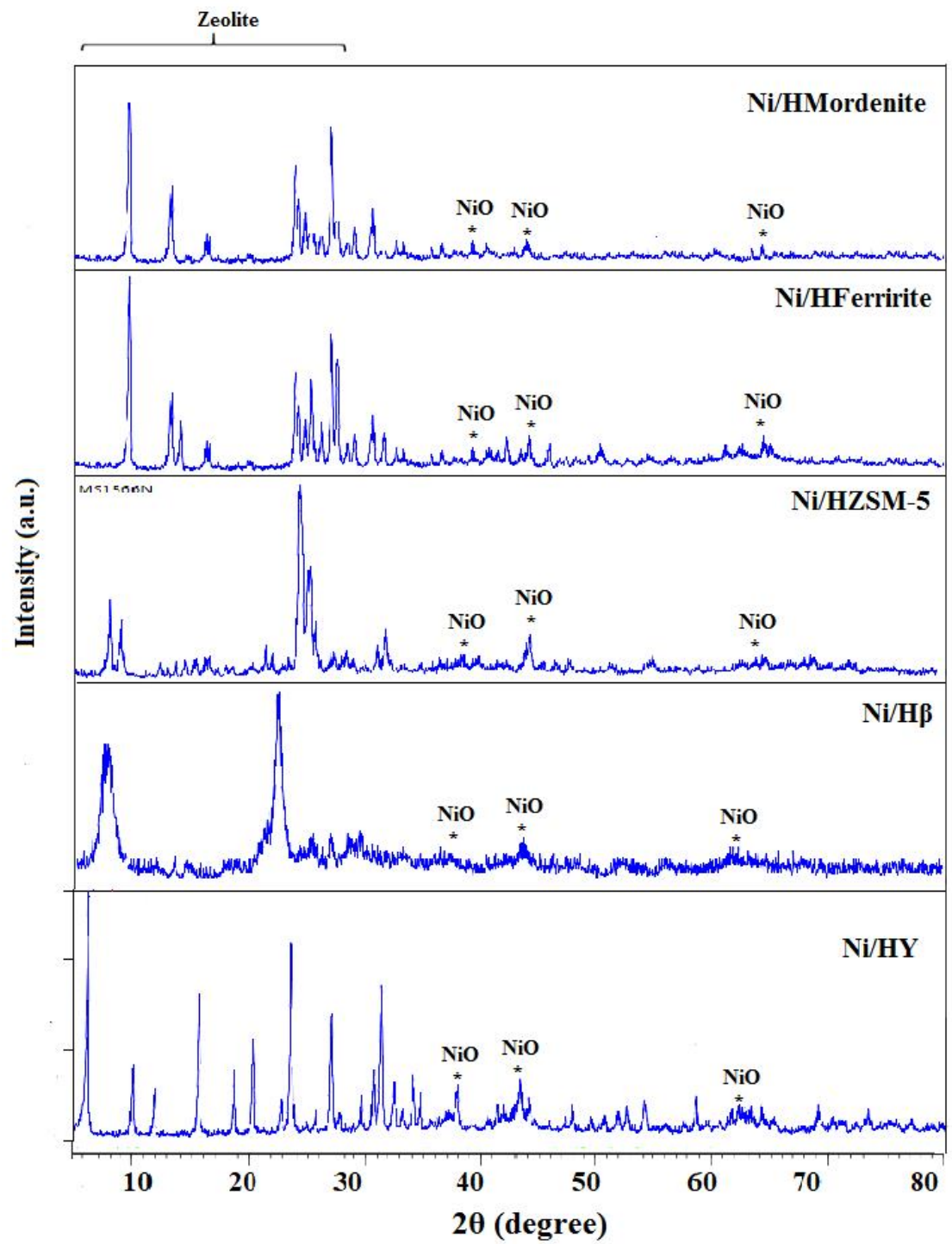

Figure 1. XRD patterns of the prepared catalysts

\section{Textural properties and chemical composition}

$\mathrm{N}_{2}$ adsorption-desorption was applied to determine the textural properties of the prepared catalysts. The results of $\mathrm{N}_{2}$ adsorption-desorption, surface areas, and other textural properties of the prepared catalysts were indicated in Table 1. 
By comparison of the textural properties of the synthesized catalysts listed in Table 1 with the manufactured properties of net zeolites, it was found that the surface area of the catalysts decreased after the incorporation of Nickel species into the zeolites. This may be due to the higher dispersion of the nanosized crystallites [33].

Table 1. The textural properties of the prepared catalysts

\begin{tabular}{|c|c|c|c|c|}
\hline Row & Catalyst & $\mathbf{S}_{\mathrm{BET}}\left(\mathbf{m}^{\mathbf{2}} \mathbf{~}^{-\mathbf{1}}\right)^{(\mathbf{a})}$ & $\mathbf{V}_{\text {total }}\left(\mathbf{c m}^{\mathbf{3}} \mathbf{/ g}\right)^{\mathbf{( b )}}$ & $\begin{array}{c}\text { Ni loading (wt. \%) } \\
\mathbf{( \mathbf { c } )}\end{array}$ \\
\hline $\mathbf{1}$ & $\mathrm{Ni} / \mathrm{Y}$ & 540 & 0.35 & 5.20 \\
\hline $\mathbf{2}$ & $\mathrm{Ni} / \beta$ & 370 & 0.66 & 4.97 \\
\hline $\mathbf{3}$ & $\mathrm{Ni} / \mathrm{ZSM}-5$ & 290 & 0.14 & 5.36 \\
\hline $\mathbf{4}$ & $\mathrm{Ni} / \mathrm{FER}$ & 260 & 0.11 & 5.08 \\
\hline $\mathbf{5}$ & $\mathrm{Ni} / \mathrm{MOR}$ & 310 & 0.16 & 5.29 \\
\hline
\end{tabular}

(a) BET surface area obtained by analyzing nitrogen adsorption data at $-196^{\circ} \mathrm{C}$ in a relative vapor pressure ranging from 0.05 to $0.30\left(\mathrm{~m}^{2} / \mathrm{g}\right)$; (b) Total pore volume estimated based on the volume adsorbed at $\mathrm{P} / \mathrm{P}_{\mathrm{o}}=0.99\left(\mathrm{~cm}^{3} / \mathrm{g}\right)$; (c) The metal loading measured by EDX

The amount of $\mathrm{Ni}$ in the prepared catalysts was determined by the EDX analysis. As shown in the last column of Table 1, a proper approximation to the theoretical $\mathrm{Ni}$ loading was performed for $\mathrm{Ni} / \mathrm{\beta}$ using this analysis, while the $\mathrm{Ni}$ loading in the other catalysts is more than one expected during preparation. As mentioned in some literatures, this exceeding amount of metal may be due to the uneven embedded metal in the support on the area detected by the EDX instrument, which generated by the microwaves applied to separate particles with rapid heating. Another reason may be the probable fewer Ni particles in the area that is not analyzed using EDX [34].

\section{TPR analysis}

The $\mathrm{H}_{2}$-TPR curves of the calcined Ni/zeolite catalysts were presented in Figure 2, which attributed to the reduction of the NiO. For all prepared $\mathrm{Ni} /$ zeolites, one obvious $\mathrm{H}_{2}$ consumption peak was observed at approximately $350^{\circ} \mathrm{C}$, which was ascribed to the peaks of $\mathrm{NiO}$ species reducing to $\mathrm{Ni}$. In fact, the TPR curves had ascending route from $280^{\circ} \mathrm{C}$ to $350^{\circ} \mathrm{C}$. Therefore, the optimum temperature for the reduction of the prepared samples was proposed to be in in this range. 


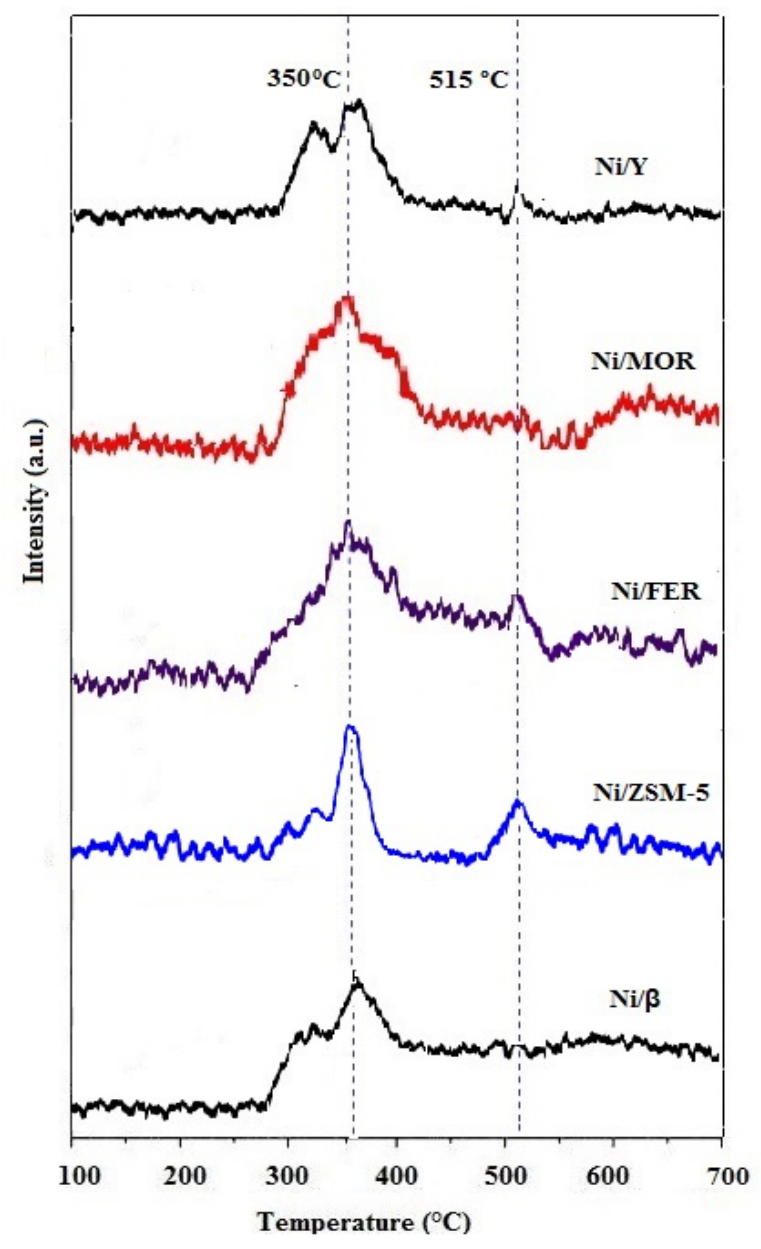

Figure 2. $\mathrm{H}_{2}$-TPR curves of the calcined Ni/zeolite catalysts

\section{Acidity analysis}

The acidic properties of the zeolites determined from $\mathrm{NH}_{3}$-TPD profiles with the corresponding strong and weak acid sites amounts were summarized in Figure 3. As observed, the acid strength of the various zeolites was different.

According to the previous studies, the reason of having a different acidity profile mainly is the difference in their intensity which refers to the amount of $\mathrm{NH}_{3}$ desorbed from the samples pretreated with $\mathrm{NH}_{3}$ chemical adsorption [35]. 


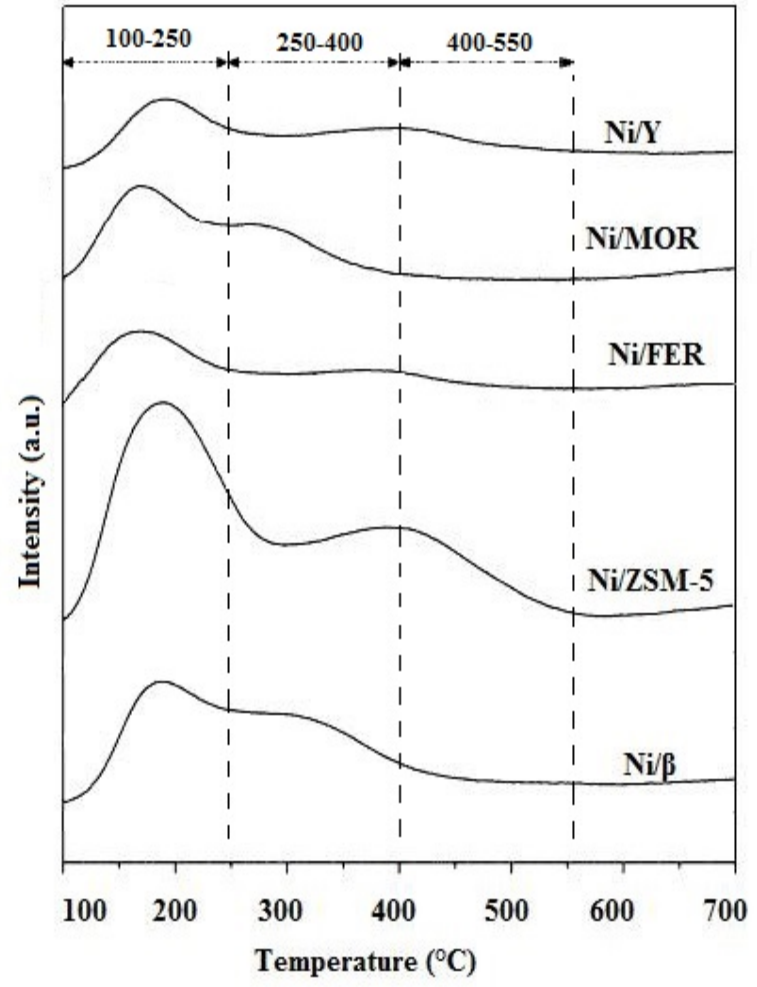

Figure 3. The profiles of $\mathrm{NH}_{3}$-TPD for the prepared catalysts

As the profiles of $\mathrm{NH}_{3}$-TPD revealed, the $\mathrm{Ni} / \mathrm{Y}$ appeared to be the sample with more weak acid sites than strong acid sites. Ni/MOR showed to have relatively high weak and medium acidity. No obvious strong acid sites observed in the case of this sample. The TPD profile of the Ni/FER presented a little acidity for all weak, medium, and strong acid sites.

The highest weak acid site was remarkable in the case of Ni/ZSM-5 catalyst. In addition, it showed significantly the most amounts of medium and strong acid sites.

$\mathrm{Ni} / \beta$ sample had more weak acidity, which went towards medium acid sites. The amounts of its strong acid sites were not appeared to be remarkable. In comparison, both weak and strong acid sites was observed to be the most in the case of the Ni/ZSM-5 and the highest acidity in the range of the medium acid sites belonged to $\mathrm{Ni} / \beta$ among five prepared samples. 


\section{Performance test results}

The collected produced liquids were subjected to physicochemical analytical tests using the methods specified by the American Standard for Testing and Materials (ASTM D1655). Among the analyzed properties, four significant properties namely density, final boiling point (FBP), flash point, and freezing point were selected to be discussed. The analysis results of these properties and their comparison to some standard fuels were given in Table 2.

Table 2. Physicochemical data of feed, produced liquids, and some standard fuels

\begin{tabular}{|c|c|c|c|c|c|}
\hline products & Property & $\begin{array}{l}\text { Density at } 15.6 \\
{ }^{\circ} \mathrm{C}\left(\mathrm{kg} / \mathrm{m}^{3}\right)\end{array}$ & $\operatorname{FBP}\left({ }^{\circ} \mathrm{C}\right)$ & $\begin{array}{c}\text { Flash point } \\
\left({ }^{\circ} \mathrm{C}\right)\end{array}$ & $\begin{array}{l}\text { Freezing point } \\
\left({ }^{\circ} \mathrm{C}\right)\end{array}$ \\
\hline \multirow{2}{*}{$\begin{array}{l}\text { Standard } \\
\text { method }\end{array}$} & ASTM D & 4052 & 86 & 3828 & 2386 \\
\hline & IP & 365 & 123 & 303 & 16 \\
\hline \multirow{7}{*}{$\begin{array}{l}\text { Products } \\
\text { over } \\
\text { Catalysts }\end{array}$} & Feed & 797.4 & 280 & 50 & -52 \\
\hline & No cat. & 800.0 & 290 & 47 & -53 \\
\hline & $\mathrm{Ni} / \mathrm{Y}$ & 799.8 & 295 & 46 & -55 \\
\hline & Ni/Mordenite & 800.1 & 289 & 49 & -51 \\
\hline & $\mathrm{Ni} / \boldsymbol{\beta}$ & 797.4 & 294 & 51 & -53 \\
\hline & Ni/ZSM5 & 799.6 & 282 & 46 & -55 \\
\hline & Ni/Ferririte & 799.2 & 297 & 48 & -44 \\
\hline \multirow{8}{*}{$\begin{array}{l}\text { Standard } \\
\text { fuels }\end{array}$} & Gasoline & Report & 170 & --- & -60 \\
\hline & kerosene & $799-815$ & 275 & 43.3 & -37.8 \\
\hline & Gasoil & $820-860$ & 385 & $51-54$ & --- \\
\hline & Jet fuel (ATK) & $775-840$ & 300 & 38 & -47 \\
\hline & JP-4 & $751-802$ & 270 & --- & -58 \\
\hline & JP-5 & $788-845$ & 300 & 60 & -46 \\
\hline & JP-7 & $779-806$ & 288 & 60 & -43.3 \\
\hline & JP-8 & $775-840$ & 300 & 38 & -47 \\
\hline
\end{tabular}

\section{Compositions of liquid products}

All components of reformed kerosene in heterogeneous conditions by hydrocarbon groups and their carbon atom number $\mathrm{Cn}$ were identified or organized. The weight percentage of reformed produced liquids were identified and calculated with the same method as described for the kerosene fractions. The results were summarized in Table 3 . In details, the identified peaks belonged to the carbon range of $\mathrm{C} 8$ to $\mathrm{C} 24$ in the presence of three prepared catalysts of $\mathrm{Ni} /$ Ferririte, $\mathrm{Ni} /$ Mordenite and $\mathrm{Ni} / \mathrm{Y}$, while the identified compounds of produced liquid in the presence of $\mathrm{Ni} / \beta$ catalyst were in the range of $\mathrm{C} 8$ to $\mathrm{C} 17$. On the other hand, feed and the produced liquid in the presence of Ni/ZSM-5 catalyst had the compounds ranged from C8 to C20. 
SYNTHESIS OF HYDROCARBON FUELS VIA SELECTIVE REFORMING OF KEROSENE OVER ...

Table 3. Summarization of compound analyses of produced liquids (wt. \%)

\begin{tabular}{|c|c|c|c|c|c|}
\hline Row & Catalyst type & N- paraffins & Isoparaffins & Cycloparaffins & Aromatics \\
\hline $\mathbf{1}$ & Fresh feed & 27.426 & 27.911 & 23.489 & 21.234 \\
\hline $\mathbf{2}$ & $\mathrm{Ni} / \mathrm{Y}$ & 24.6987 & 12.4439 & 5.2609 & 57.5965 \\
\hline $\mathbf{3}$ & $\mathrm{Ni} /$ Mordenite & 24.1737 & 38.2285 & 7.8715 & 29.7263 \\
\hline $\mathbf{4}$ & $\mathrm{Ni} / \boldsymbol{\beta}$ & 22.7547 & 34.0740 & 34.9075 & 8.2639 \\
\hline $\mathbf{5}$ & $\mathrm{Ni} / \mathrm{ZSM}-5$ & 4.3875 & 30.3861 & 46.2826 & 18.9438 \\
\hline $\mathbf{6}$ & $\mathrm{Ni} /$ Ferririte & 25.6899 & 38.8542 & 4.7488 & 30.7071 \\
\hline
\end{tabular}

As the Figure 4 shows, the amounts of some compositions are more than other ones in produced fuels.

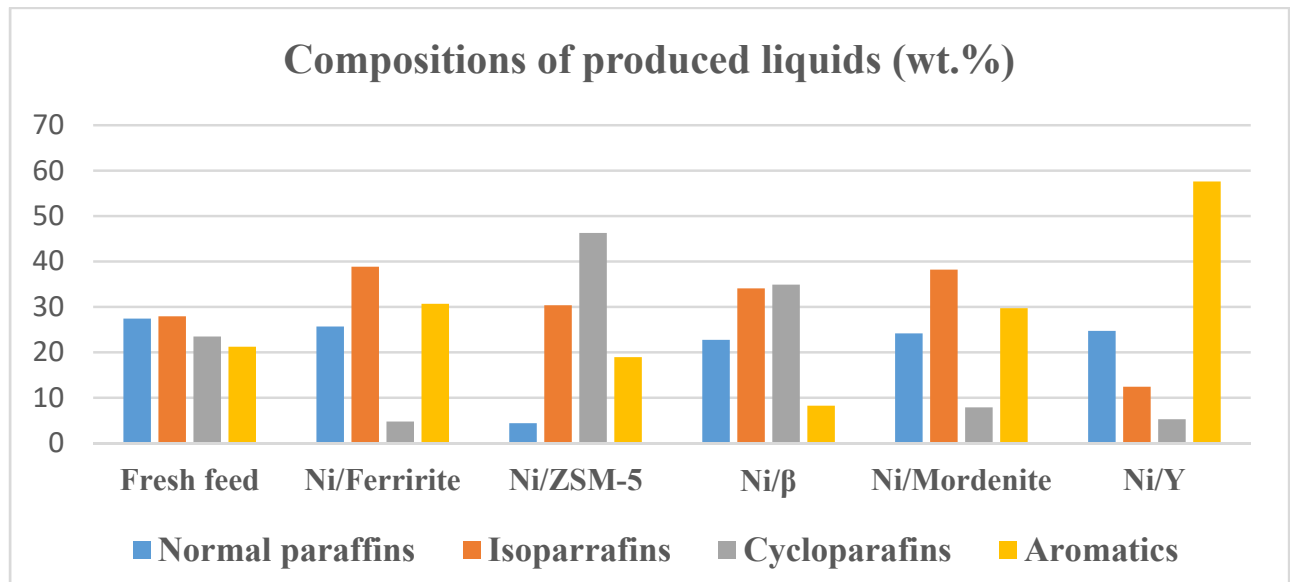

Figure 4. Distribution of the hydrocarbon groups contained in the produced liquids

The hydrocarbons are categorized by their carbon chain length into the gasoline (C5-C10), jet fuel (C9-C15), diesel (C14-C20), and lubricant (C19-C25) [34, 44]. As shown in the Table 4, the liquid products were classified according to these carbon chain ranges.

Table 4. The classification of liquid products according to the carbon chain range

\begin{tabular}{|c|c|c|c|c|c|}
\hline Row & Catalyst & $\begin{array}{c}\text { Gasoline } \\
\text { (C5-C10) }\end{array}$ & $\begin{array}{c}\text { Jet fuel } \\
\text { (C9-C15) }\end{array}$ & $\begin{array}{c}\text { Diesel } \\
\text { (C14-C20) }\end{array}$ & $\begin{array}{c}\text { Lubricant } \\
\text { (C19-C25) }\end{array}$ \\
\hline $\mathbf{1}$ & $\mathrm{Ni} / \mathrm{Y}$ & 18.65 & 64.72 & 16.52 & 0.11 \\
\hline $\mathbf{2}$ & $\mathrm{Ni} / \mathrm{ZSM}-5$ & 17.37 & 80.42 & 2.19 & 0.02 \\
\hline $\mathbf{3}$ & $\mathrm{Ni} / \beta$ & 28.40 & 68.72 & 2.88 & 0 \\
\hline $\mathbf{4}$ & $\mathrm{Ni} / \mathrm{MOR}$ & 18.26 & 64.93 & 16.71 & 0.10 \\
\hline $\mathbf{5}$ & $\mathrm{Ni} / \mathrm{FER}$ & 18.96 & 64.49 & 16.42 & 0.13 \\
\hline
\end{tabular}


According to these results, $\mathrm{Ni} / \mathrm{\beta}$ produced the lowest fuels with no carbon numbers in the range of lubricants. As anticipated, the reforming of kerosene showed an enhanced capability of jet fuel products. This process led to at least $64 \%$ jet fuel over each catalyst. However, the Ni/ZSM-5 produced more cycloparaffins in comparison to other samples. Therefore, this catalyst produced highest jet fuel with the highest quality.

\section{Effect of catalyst characters on the liquid products}

The effect of some characters of the prepared catalysts on compositions of produced liquids is discussed in this section.

Pore sizes of the applied zeolite were in the order of $\mathrm{Ni} /$ Ferririte $<$ $\mathrm{Ni} / Z S M-5<\mathrm{Ni} /$ Mordenite $<\mathrm{Ni} / \beta<\mathrm{Ni} / Y$. Generally, micropore zeolites such as Ferririte have lower activity than those with mesopore (ZSM-5) and macropore ( $Y$, Mordenite, and Beta). It is not in conflict with increasing the catalytic activity with decreasing the particle size. The kerosene- range molecules diffuse toward pores and react on the surface of catalyst. Since the Ferririte pore is smaller than some molecules such as cycloparaffins, a few amounts of these components were produced over this zeolite.

In the case of $Y$ and Mordenite catalysts, however the few amounts of cycloparaffins may be due to the difference of acid sites strength and concentration. Instead, their polyaromatics were more, which may be due to macroporous structures of these catalysts. As already noted the acidity of the catalysts directly influences on some properties of the produced liquids. The acidity power (less Si/Al ratio) of applied catalysts was in the order of $\mathrm{Ni} / \beta<\mathrm{Ni} / Z \mathrm{SM}-5<\mathrm{Ni} /$ Ferririte $<\mathrm{Ni} /$ Mordenite $<\mathrm{Ni} / \mathrm{Y}$. Note that acidity of Mordenite and $\mathrm{Y}$ has increased after ion exchange of $\mathrm{Na}$-form zeolite samples to $\mathrm{NH}_{4}{ }^{+}$form. Strong acid sites on catalysts would be the main reason for the catalyst deactivation (i.e. coke deposition and weak acid site may go forwards reforming process through multi-step pathway and therefore undesired side reactions. In other words, an optimum Si/Al ratio would be desirable [36]. As shown in Figure 5, zeolites have an important role to go selectively the dehydrocyclization reaction towards and supported metals can promote the formation of aromatics. The stronger- acidic catalysts have greater activity than that of the weaker-acidic catalyst. In this paper, Y zeolite with highest acidic power produced the most aromatic contents. 


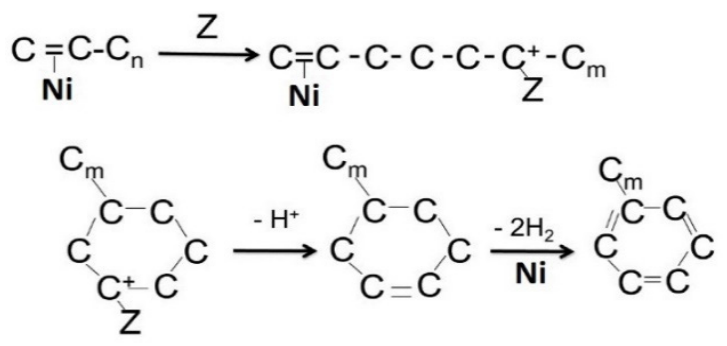

$Z=$ an acid site of zeolite

Figure 5. Formation routes of aromatic hydrocarbons from aliphatic ones on a Ni/ zeolite catalyst [37]

Reforming process in the presence of zeolites with 2 or 3D channel pore leads to produce a different fuel than 1D pore channel. As a result, a strong dependence of reforming process on the channel structures of catalysts was observed in order that some huge hydrocarbon components could not be formed or passed through 1D channel zeolites such as Mordenite. As well, 2D channel ZSM-5 zeolite made the limpidity of passing some components in comparison to 3D zeolites such as $Y$ and $\beta$. In other words, shape selectivity of ZSM-5 is a key parameter in improving quality of products [38].

\section{CONCLUSIONS}

In this paper, reforming of kerosene was investigated over five $5 \% \mathrm{Ni} / z e o l i t e$ catalysts. Among the series studied, ZSM- 5 and $\beta$ catalysts direct the reaction forwards the dehydrocyclization by increasing the naphthenic compounds of fuel and hence it would be proposed to apply these catalysts to production of some type of jet fuels. These two catalysts had the weaker acidic power than other prepared catalysts. Therefore, they did not favor the formation of aromatics in comparison to $\mathrm{Y}$, Mordenite and Ferririte catalysts, which would improve octane number of gasoline if they were applied to aromatization reactions. Y zeolite had the ability to produce more aromatics, which is suitable to produce high quality gasoline by increasing its octane number. Mordenite produced a product with high isoparaffin content. The high strong acid sites in the $\mathrm{Y}$, Mordenite and Ferririte zeolites lead to side reactions such as cracking, and consequently more aromatic formation in the liquid products.

Its macroporous structure along with lowest Si/Al ratio and 3D channel structure would be the best reason to introduce $Y$ zeolite as a suitable catalyst to further researches in the field of aromatization. The similarity of products to high-energy jet propellant fuels was maximized when $\mathrm{Ni} /$ ZSM-5 was used in this study. 


\section{EXPERIMENTAL SECTION}

\section{Materials}

The properties of kerosene supplied by Tehran Oil Refinery Company (TORC) were reported in Table 5.

Table 5. Specifications of supplied kerosene by TORC

\begin{tabular}{|c|c|c|c|}
\hline Property & Unit & Test method & Feed properties \\
\hline Density at $15.6{ }^{\circ} \mathrm{C}$ & $\mathrm{kg} / \mathrm{m}^{3}$ & D 1298 & 797.4 \\
\hline $\begin{array}{c}\text { Distillation } \\
\text { IBP } \\
185{ }^{\circ} \mathrm{C} \\
200{ }^{\circ} \mathrm{C} \\
210{ }^{\circ} \mathrm{C} \\
235{ }^{\circ} \mathrm{C} \\
\text { FBP }\end{array}$ & $\begin{array}{c}{ }^{\circ} \mathrm{C} \\
\% \text { vol. } \\
\% \text { vol. } \\
\% \text { vol. } \\
\% \text { vol. } \\
{ }^{\circ} \mathrm{C}\end{array}$ & D 86 & $\begin{array}{l}156 \\
23.9 \\
48.4 \\
64.1 \\
90.9 \\
260\end{array}$ \\
\hline Sulfur & \% wt. & D 1552 & 0.09 \\
\hline Flash point & ${ }^{\circ} \mathrm{C}$ & D 3828 & 50 \\
\hline Freezing point & ${ }^{\circ} \mathrm{C}$ & D 2386 & -52 \\
\hline Acidity & $\%$ vol. & D 3242 & $0.5 \mathrm{~mL} / 0.5 \mathrm{~mL}$ \\
\hline Aromatic content & $\%$ vol. & D 6379 & $21.3 \%$ \\
\hline
\end{tabular}

Nickel nitrate hexahydrate $\left(\mathrm{Ni}\left(\mathrm{NO}_{3}\right)_{2} \cdot 6 \mathrm{H}_{2} \mathrm{O}\right)$, sodium carbonate $\left(\mathrm{Na}_{2} \mathrm{CO}_{3}\right)$ applied to prepare the Ni/zeolite catalysts and ammonium nitrate $\left(\mathrm{NH}_{4} \mathrm{NO}_{3}\right)$ used for zeolite ion exchange were purchased from Merck Company (Germany). Five applied zeolites to the reforming of kerosene were purchased from Zeolyst Company (USA) with the typical properties reported by manufacturer and more details of their properties were illustrated in Table 6.

Table 6. Physical characteristics of zeolite powders as reported by manufacturer

\begin{tabular}{|c|c|c|c|c|c|c|}
\hline Row & Properties & $\mathbf{Y}$ & Mordenite & $\boldsymbol{\beta}$ & ZSM-5 & Ferririte \\
\hline $\mathbf{1}$ & Zeolyst product & CVB 100 & CVB 10A & CP 814 E & CVB 2314 & CP 914 C \\
\hline $\mathbf{2}$ & IZA code & FAU & MOR & BEA & MFI & FER \\
\hline $\mathbf{3}$ & Si/Al ratio & 5.1 & 13 & 25 & 23 & 20 \\
\hline $\mathbf{4}$ & Channel system & $12-12$ & $12-12$ & $12-12$ & $10-10$ & $8-8$ \\
\hline $\mathbf{5}$ & Pore size $(\AA)$ & $7.4 \times 7.4$ & $6.5 \times 7.0$ & $7 \times 6.5$ & $5.6 \times 5.3$ & $3.5 \times 4.8$ \\
\hline $\mathbf{6}$ & Pore shape & Circular & Circular & Elliptical & Elliptical & Elliptical \\
\hline $\mathbf{7}$ & Surface area & 900 & 425 & 680 & 425 & 400 \\
\hline $\mathbf{8}$ & Average pore & 55.95 & 42.73 & 39.89 & 41.85 & 37.32 \\
\hline
\end{tabular}




\section{Catalyst preparation and characterization}

To prepare the catalysts, two Na-form zeolites i.e. Mordenite and $Y$ zeolites were ion-exchanged to ammonium form using $\mathrm{NH}_{4} \mathrm{NO}_{3}$ solution $(0.1 \mathrm{~mol} / \mathrm{L})$. The deposition- precipitation method was applied to prepare the catalysts. In detail, the $\mathrm{Na}_{2} \mathrm{CO}_{3}(1 \mathrm{M})$ solution was added into the aqueous solution of $1 \mathrm{M}$ metal nitrate $\left(\mathrm{Ni}\left(\mathrm{NO}_{3}\right)_{2} \cdot 6 \mathrm{H}_{2} \mathrm{O}\right)$ at $70^{\circ} \mathrm{C}$ in a controlled rate. The solution was subject to continuous stirring by $700-1000 \mathrm{rpm}$ and the $\mathrm{pH}$ of the solution was kept up around $7 \pm 0.2$. After that, the solution was aged at room temperature for $30 \mathrm{~min}$, followed by filtering three times, and rinsing to obtain precipitate. To deposit the support on the catalyst, zeolite was added to the deionized water and stirred in the room temperature to form a uniform mixture. Then, the precipitate was added to the performed solution. The obtained solution was aged $1 \mathrm{~h}$ while stirred slowly in order to deposit the support on the catalyst suitably, followed by filtration. Subsequently, the obtained solid was dried at $110^{\circ} \mathrm{C}$ in air overnight and calcined at $550^{\circ} \mathrm{C}$ in airflow for $5 \mathrm{~h}$ in order to convert to the $\mathrm{H}$ form. Sieve analysis was performed using two US standard test sieves (ASTM E.11) with mesh numbers of 20 and 40 with the sieve opening of $0.850 \mathrm{~mm}$ and $0.420 \mathrm{~mm}$, respectively.

$\mathrm{X}$-ray powder diffraction (XRD) method was used to analyze the crystal structure of the catalysts. In fact, higher peaks confirm more crystallinity of the catalysts. XRD measurements of the samples were performed using a Philips PW-3710 diffractometer equipped with a nickel filtered $\mathrm{Cu}$ - Ka radiation $(\lambda=$ $1.5418^{\circ} \mathrm{A}$ ) covert $2 \theta$ between $5^{\circ}$ and $80^{\circ}$. The formation of cubic phase of $\mathrm{NiO}$ (JCPDS Card 47-1049) investigated to XRD patterns, in which the distinct peaks at $2 \theta$ of $37.26^{\circ}, 43.29^{\circ}, 62.88^{\circ}, 75.42^{\circ}$, and $79.41^{\circ}$ as peaks of cubic NiO crystals with various diffraction (111), (200), (220), (311), and (222) planes of the face-centered cubic NiO (JCPDS 47-1049), respectively [39].

The $\mathrm{Ni}$ content of the prepared catalysts was determined by an energy dispersive X-ray (EDX) spectrometer (Zeiss Gemini Leo 1530). The surface area and pore volume of the samples were measured at $-196^{\circ} \mathrm{C}$ (77K) using nitrogen adsorption according to the Brunauer-Emmett-Teller method (BET) method (by a CHEMBET-3000, Quantachrome Instruments, Germany). ICP (Inductively coupled plasma) emission spectrometer (Ultimo Expert, Horiba Scientific) was employed for measurement of the chemical composition of zeolites in this study. Temperature-programmed reduction (TPR) measurements of the catalysts were carried out at $550^{\circ} \mathrm{C}$ for $30 \mathrm{~min}$ in air. The second stage ramped the temperature from $100^{\circ} \mathrm{C}$ to $700^{\circ} \mathrm{C}$ at $5^{\circ} \mathrm{C} / \mathrm{min}$ in $3 \% \mathrm{H}_{2}$ diluted in argon. To investigate the consumption of $\mathrm{H}_{2}$, a thermal conductivity detector (TCD) was applied. 
Ammonia temperature programmed desorption ( $\mathrm{NH}_{3}$-TPD) with a BELCAT-M instrument (BEL Japan Inc.) with a TCD detector was employed to study the acid properties of the catalysts. A calibration curve was applied to calculate the ammonia amount by converting the peak area to concentration, and the number of weak, medium, and strong acidic sites was calculated by dividing the integrated peak area into ranges of 100-250, 250450 , and $450-600^{\circ} \mathrm{C}$, respectively [40].

\section{Catalyst performance tests}

Catalytic tests via reforming process were carried out in a stainless steel fixed-bed reactor with an internal diameter of $10 \mathrm{~mm}$ and a length of $150 \mathrm{~mm}$. A schematic diagram of the experimental setup for the catalytic reforming of kerosene is shown in Scheme 1.

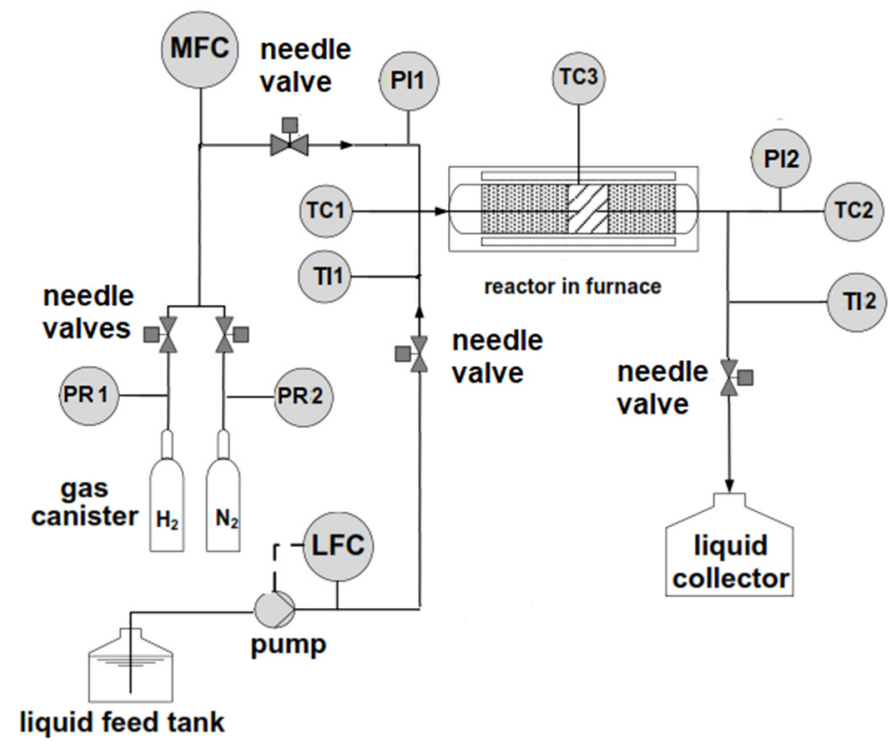

Scheme 1. Schematic diagram of the laboratory- scale experimental setup of reforming system. LFC- liquid flow controller; MFC- mass flow controller; pump-peristaltic pump; TC-thermocouple; Tl- temperature indicator;

$\mathrm{PI}$ - pressure indicator; $\mathrm{PR}$ - pressure regulator

Prior to the reforming of kerosene, reduction was performed at $300^{\circ} \mathrm{C}$ for $1 \mathrm{~h}$ in pure $\mathrm{H}_{2}$ with a flowrate of $50 \mathrm{~mL} / \mathrm{min}$. To activate the catalyst, $\mathrm{N}_{2}$ was flowed in-situ for $10 \mathrm{~min}$ with $70 \mathrm{cc} / \mathrm{min}$ rate. A preheater was applied to heat kerosene initially with temperature of $300^{\circ} \mathrm{C}$. Kerosene with a flow rate of 
$5 \mathrm{~mL} \mathrm{~min}^{-1}$ was introduced into the preheater by the peristaltic pump (TEC1, AQUA, Italy). Then, the heated feed was entered to the reactor at the temperature reaction $\left(450^{\circ} \mathrm{C}\right)$. A mass flow controller (Brooks, 5850) was employed for controlling of the feed flow rate. The liquid products were collected using two-step traps to be analysed. The products of reforming reaction were first collected in a hot trap followed by a cold trap with ice water to avoid produced liquid phase condensed and stranded in the system.

The collected liquid products were analysed by an Agilent $6890 \mathrm{~N}$ gas chromatography (GC) equipped with a flame ionization detector (FID) and a $\mathrm{DH}$ capillary column $(40 \mathrm{~m})$. Injection temperature was set to $300^{\circ} \mathrm{C}$. Column temperature was initially increased from 40 to $100^{\circ} \mathrm{C}$ at a rate of $2^{\circ} \mathrm{C} / \mathrm{min}$, and then increased to $300^{\circ} \mathrm{C}$ at a rate of $10^{\circ} \mathrm{C} / \mathrm{min}$ for $8 \mathrm{~min}$.

\section{ACKNOWLEDGMENTS}

Financial support of this work by the faculty of chemistry and chemical engineering of Malek-Ashtar University of Technology (MUT) is gratefully acknowledged.

\section{REFERENCES}

1. Global Energy \& $\mathrm{CO}_{2}$ Status Report; International Energy Agency (IEA): Paris, France, 2018.

2. J.C. Serrano-Ruiz; J.A. Dumesic; Energy Env. Sci., 2011, 4, 83-99.

3. M. A. Díaz-Pérez; J. C. Serrano-Ruiz; Molecules, 2020, 25, 802-820.

4. S. Toamasek; Z. Varga; J. Hancsók; Fuel Process. Technol., 2020, 197, 106197. https://doi.org/10.1016/j.fuproc.2019.106197

5. J.D. Woodroffe; B. G. Harvey; energy fuels, 2020, https://dx.doi.org/10.1021/acs.energyfuels.0c00274

6. F. Zaera; Appl. Catal. A., 2002, 229, 75-91.

7. A. Klerk; Molecules, 2018, 23, 115-126.

8. M. Shahabuddin; M.T. Alam; B.B. Krishn; T. Bhaskar; G. Perkins; Bior Tech., 2020, 312, 123596.

9. T.K. Habibie; B. H. Susanto; M. F. Carli; E3S Web of Conferences 67, 2018.

10. S. Tomasek; Z. Varga; J. Hancsók; Fuel Process. Technol., 2020, 197, 106197.

11. H. Wang; S. Yan; M. Kim; S.O. Salley; K.Y.S. Ng; Current Catalysis, 2012, 1, 132-139.

12. X. Li; A.A. Alwakwak; F. Rezaei; A.A. Rownaghi; ACS Appl. Energy Mater., 2018, 1 (6), 2740-2748.

13. G.J. Antos; A.M. Aitani; Catalytic Naphtha Reforming, 2nd ed., Marcel Dekker, New York, 2004, pp. 335-349.

14. C.E. Xu; Catalytic Reforming Process and Engineering, China Petrochemical Press, Beijing, 2006, pp. 1-26. 
15. P. Zhang; Y. Yang; Z. Li; B. Liu; C. Hu; Catal. Today, 2019, https://doi.org/10.1016/j.cattod.2019.07.032.

16. M. Shahinuzzamana; Z. Yaakob; Y. Ahmed; Renew. Sust. Energ. Rev., 2017, http://dx.doi.org/10.1016/j.rser.2017.01.162.

17. J. Y. Kim; J. Moon; J.H. Lee; X. Jin; J.W. Choi; Fuel, 2020, 279, 118484.

18. F. Thomas; J. Degnan; Top Catal., 2020, 13, 349-356.

19. A. Ishihara; Fuel Process Technol., 2019, 194, 106-116.

20. W. Namchota; S. Jitkarnka; J Anal Appl Pyrolysis., 2016, 118, 86-97.

21. H. Kim; D. Kim; Y. K. Park; J. K. Jeon; Res Chem Intermed, 2018, 44, 3823-3833.

22. D. Yao; H. Yang; H. Chena; P.T. Williams, Appl. Catal. B Environ., 2018, 227, 477- 487.

23. X. Yang; J. Da; H. Yu; H. Wang; Fuel, 2016, 179, 353-361.

24. L. Liu; L. Hong; AIChE Journal, 2011, 57, 3143-3152.

25. A.J. Maia; B. Louis; Y.L. Lam; M.M. Pereira; J. Catal., 2010, 269 (1), 103-109.

26. M. Lallemand; O.A. Rusu; E. Dumitriu; A. Finiels; F. Fajula; V. Hulea; Appl. Catal. A., 2008, 338, 37-43.

27. L. Chen; X. Wang, H. Guo; X. Guo; Y. Wang; H. Liu; G. Li, Catal. Commun., 2007, 8, 416-423.

28. P. Yan; J. Mensah; A. Adesina; E. Kennedy; M. Stockenhuber; Appl. Catal. B Environ., 2020, 267, 118690.

29. A. Marcilla; A. Gómez-Siurana; F. Valdés; J. Anal. Appl. Pyrolysis, 2007, 79, 433-442.

30. A. Kant; Y. He; A. Jawad; X. Li; F. Rezaei; J.D. Smith; A. A. Rownaghi; Chem. Eng. J., 2017, 317, 1-8.

31. M. A. Atanga, F. Rezaei, A. Jawad, M. Fitch, A. A. Rownaghi, Appl. Catal. B Environ., 2018, 220, 429-445.

32. S. C. Qi; X. Y. Wei; Z. M. Zong; J. Hayashi; X. H. Yuan; L. B. Sun; Chem Cat Chem., 2013, 5, 3543-3547.

33. K.B. Golubev; K. Zhang; X. Su; N.V. Kolesnichenko; W. Wu; Catal Commun., 2021, 149, 106176.

34. T. K. Habibie; B.H.Susanto; M. F. Carli; E3S Web of Conferences 67, 02024, 2018, 3rd i-TREC 2018.

35. M.Y. Choo; L. E. Oi; T. J. Daou; T. C. Ling; Y.C. Lin; G. Centi; E. P. Ng; J. C. Juan; Materials, 2020, 13, 3104.

36. X. Zou; X. Wang; L. Li; K. Shen; X. Lu; W. Ding; Int J Hydrog Energy, 2010, 35, $12191-12200$.

37. A. Ishihara; R. Ishida; T. Ogiyama; H. Nasu, T. Hashimoto, Fuel Process. Technol., 2017, 161,17-22.

38. R. Nishu; M. Liu; M. Rahman; M. Sarker, M. Chai; C. Li; J. Cai; Fuel Process. Technol., 2020, https://doi.org/10.1016/j.fuproc.2019.106301.

39. S. Zulkepli; J.C. Juan; H.V. Lee; N.S.A. Rahman; P.L. Show; E.P. Ng; Energy Convers. Manag., 2018, 165, 495-508.

40. C. Wang; Q. Liu; J. Song; W. Li; P. Li; R. Xu; H. Ma; Z. Tian, Catal. Today, 2014, 234, 153-160. 